\title{
$\begin{array}{ll}\text { Research Square } & \text { Preprints are preliminary reports that have not undergone peer review. }\end{array}$ or referenced by the media as validated information. \\ Factors Associated with Health Checkups and Cancer Screening Participation Among Family Caregivers of Individuals with Dementia
}

\section{Bomgyeol Kim}

Yonsei University https://orcid.org/0000-0002-3670-4988

\section{Yejin Lee}

Eulji University

\section{Jin-Won Noh}

Dankook University - Cheonan Campus

Tae Hyun Kim ( $\nabla$ thkim@yuhs.ac)

Yonsei University, Korea

\section{Research article}

Keywords: Health checkup, Cancer screening, Informal caregivers, Dementia care

Posted Date: August 18th, 2020

DOI: https://doi.org/10.21203/rs.3.rs-53533/v1

License: (우 This work is licensed under a Creative Commons Attribution 4.0 International License. Read Full License 


\section{Abstract}

Background: Providing care for dementia can negatively influence the physical health and health behaviors of family caregivers. A better understanding of the factors associated with health checkups and cancer screening is vital to better develop effective interventions. Thus, this study aimed to identify factors associated with participation in health checkups and cancer screening among family caregivers of individuals with dementia.

Methods: This study analyzed a total of 2,414 family caregivers of individuals with dementia, using the Korea Community Health Survey (KCHS) data in 2017. A binomial logistic regression analysis was performed to identify demographic, socioeconomic, and health status factors associated with health checkups and cancer screening participation among family caregivers of individuals with dementia.

Results: The health checkups and cancer screening rates among family caregivers of individuals with dementia patients were $68.7 \%$ and $61.4 \%$, respectively, which were significantly lower than those who do not provide care. Those with lower education level had lower odds ratios for both health checkups(OR: 0.60) and cancer screening(OR: 0.59). In addition, symptoms of depression were associated with lower participation(Health checkups OR: 0.67; Cancer screening OR: 0.65).

Conclusions: It is needed to develop more targeted disease prevention and management strategies for family caregivers of individuals with dementia, particularly those with lower education level and symptoms of depression.

\section{Background}

Dementia, which affects about $10.16 \%$ of older Korean adults, has no cure despite medical advances, and it poses a significant burden on patients themselves as well as their families [1,2]. Many national health policies are focused on effective and efficient ways to support dementia patients in order for them to live as independently as possible in their communities [3]. It has been known thanks to prior studies that family caregivers play an important role in maintaining the lives of dementia patients in their communities $[4,5]$. Family caregivers of individuals with dementia experience stress, burnout, depression, and socioeconomic difficulties caused by prolonged caregiving [6]. Family caregivers of individuals with dementia are considered "secondary patients" or "hidden patients," and caring for older adults with dementia in the home setting is believed to be more burdensome than caring for a terminal cancer patient $[7,8]$. As informal care often has a negative impact on the health of families providing care, the need to pay attention to the health of families of dementia patients has increased [9].

As dementia progresses, the need for care increases significantly, and professional services are often needed to support the health and welfare of families to supplement their care and support their activities [3]. To ensure a healthy life for families providing care, it is important to check their health routinely to detect and treat abnormalities early to prevent them from developing further complications. Health checkups and cancer screening are a disease prevention strategy for detecting, treating, and managing a disease early, to prevent premature death or severe complications $[10,11]$. Preventive treatment service through health 
checkups and cancer screening can lower potential medical costs and can treat diseases with relatively simple methods yielding good outcomes [12]. The government strongly recommends regular health checkups, as they identify diseases in a timely manner [13]. Thus, health checkups and cancer screening are effective and essential health behaviors for the early detection of diseases [14]. However, because of the prolonged burden of informal care to the dementia patients, those who live with them may not get a chance to attend health checkups and cancer screening. Increasing the health checkups rate among families providing informal care to dementia patients is critical for enhancing their health and quality of life. Therefore, it is important to examine the health checkups rate among families of dementia patients and identify factors associated with health checkups and cancer screening to effectively promote screening.

Previous studies identified several factors associated with health checkups rate. The factors associated with health checkup participation included gender, age, area of residence, marital status, education level, type of health insurance, household income, subjective health status, chronic disease, depression, smoking, drinking, and regular exercise [15-17]. Further, the factors associated with cancer screening participation included gender, age, area of residence, type of health insurance, private health insurance, monthly household income, chronic disease, health checkups intention, concern about the risk of cancer, history of cancer screening, and regular exercise $[11,18,19]$. Considering this, it would be necessary to examine whether these factors would influence those with dementia equally.

Thus, amid the rising number of dementia patients and consequent rise in the caregiving burden on their families, this study aims to identify factors associated with participating in health checkups and cancer screening among family caregivers of individuals with dementia.

\section{Methods}

\section{Data and study population}

This study used raw data from the 2017 Korea Community Health Survey (KCHS) conducted by the Korea Centers for Disease Control and Prevention (KCDC). The KCHS is a general statistic approved by Statistics Korea (Approval number 117075) conducted per Article 4 (Community health survey) of the Regional Public Health Act and Article 2 (Method and content of the community health survey) of the Enforcement Decree of the same Act [20]. After selecting a sample plot through probability proportional to size sampling in tong, ban, and ri units, households for the survey were selected through systematic sampling. Trained examiners visited each of the selected households and conducted a face-to-face interview survey using computerassisted personal interviewing (CAPI) [20]. Data from the KCHS are open-data and can be used as primary data through The KCHS website after submitting a data usage plan. Of the total 228,381 respondents, 2,414 family caregivers of individuals with dementia who answered "yes" to the following question such as "Does your household currently include a patient diagnosed with dementia by a physician?" were selected as participants of this study.

\section{Measurements}




\section{Dependent Variable}

The dependent variables of this study were health checkups and cancer screening participation. Health checkups participation was assessed using the question "Have you had health checkups (excluding cancer screening) in the past two years just to check your health status even though you don't have any particular health problems?" The health checkups include the national general health checkups which are conducted every other year. Those who answered "no" to the question were classified as people who had not received health checkups, and those who answered "yes" were classified as people who had received health checkups.

Cancer screening participation was also assessed using the following question: "Have you had a cancer screening in the past two years just to check your health status even though you don't have any particular health problems?" The cancer screenings include the national cancer screening for stomach cancer, liver cancer, colon cancer, breast cancer, cervical cancer, and lung cancer. Those who answered "no" to the question were classified as people who had not received cancer screening, and those who answered "yes" were classified as people who had received cancer screening.

\section{Independent Variables}

The following demographic factors were assessed: gender, age, and marital status. Age was divided into 1944 years, 45-64 years, and $\geq 65$ years. Marital status was classified into single, married, and other (divorced, widowed, separated) using the marital status item. Area of residence was classified into capital (Seoul Special City, Incheon Metropolitan City, and Gyeonggi Province) and non-capital (all other cities and provinces).

As socioeconomic factors, education level, occupation category, and income level were assessed. Education level was classified into below elementary school graduates, middle school graduates, high school graduates, and college graduates or higher using the highest education and graduation items. Occupation category was classified into white collar (managers, professionals and relevant workers, office workers), sales and service (service workers, sales associates), blue collar (agricultural, forestry, and fishery workers, technicians and relevant technical workers, device, machine manipulation and assembly workers, and elementary workers), and others (students, housewives, unemployed). Income level was classified into $<2$ million KRW, 2-4 million KRW, and > 4 million KRW.

As health status factors, subjective health status, stress levels, symptoms of depression, and chronic disease were assessed. Subjective health status and stress levels comprise a table which is self-reported by subjects. Subjective health status was classified into good (very good and good), moderate (moderate), and poor (poor and very poor). Subjective stress levels were assessed based on daily levels of stress and classified into very high, high, low, and very low. Depression was classified as "no" for mild depression below 9 points and "yes" for severe depression above 9 points using the PHQ-9. Chronic disease was classified into "yes" for those who had one or more of the chronic diseases investigated in the KCHS (hypertension, diabetes mellitus, dyslipidemia, stroke, myocardial infarction, arthritis, cataract). 


\section{Statistical analysis}

The general characteristics and distributions for each factor were analyzed using frequency analysis, and the data were presented as frequencies and percentages. The associations of each factor with health checkups and cancer screening participation were analyzed with likelihood ratio tests. Factors associated with health checkups and cancer screening participation were identified using binomial logistic regression analysis. Data were statistically processed using the SPSS 22.0 software.

\section{Results}

\section{Comparison of health checkups and cancer screening rates among family caregivers of individuals with/without dementia}

Table 1 shows the comparison of health checkups and cancer screening rates among family caregivers of individuals with/without dementia. The health checkup rate of individuals without dementia patients was $73.0 \%$ and their cancer screening rate was $63.4 \%$. On the other hand, the health checkup rate of family caregivers of individuals with dementia patients was $68.7 \%$ with a cancer screening rate of $61.4 \%$.

Table 1

Comparison of health checkups and cancer screening participation among individuals with/without dementia

\begin{tabular}{|lllll|}
\hline Variable & \multicolumn{2}{l}{ Health checkups } & \multicolumn{2}{l|}{ Cancer screening } \\
\cline { 2 - 5 } & Yes & No & Yes & No \\
\cline { 2 - 5 } & $\mathbf{N}(\%)$ & $\mathbf{N}(\%)$ & $\mathbf{N}(\%)$ & $\mathbf{N}(\%)$ \\
\hline $\begin{array}{l}\text { Family caregivers of individuals with } \\
\text { dementia (n=2,414) }\end{array}$ & $1,658(68.7)$ & $756(31.3)$ & $1,482(61.4)$ & $932(38.6)$ \\
\hline $\begin{array}{l}\text { Individuals without dementia } \\
\text { (n=221,451) }\end{array}$ & $161,638(73.0)$ & $59,813(27.0)$ & $140,485(63.4)$ & $80,966(36.6)$ \\
\hline
\end{tabular}

\section{Differences in health checkups and cancer screening participation according to general characteristics}

Table 2 shows the differences in health checkups and cancer screening participation according to general characteristics. Health checkups participation significantly differed according to age, marital status, area of residence, education level, occupation category, income level, symptoms of depression, and chronic disease. Cancer screening participation significantly differed according to gender, age, marital status, area of residence, occupation category, symptoms of depression, and chronic disease. 
Table 2

Differences in health checkups and cancer screening participation according to general characteristics

\begin{tabular}{|c|c|c|c|c|c|c|c|}
\hline \multirow[t]{3}{*}{ Variable } & \multirow{3}{*}{$\begin{array}{l}\text { Total } \\
(\mathrm{N}=2,414)\end{array}$} & \multicolumn{3}{|c|}{ Health checkups participation } & \multicolumn{3}{|c|}{ Cancer screening participation } \\
\hline & & $\begin{array}{l}\text { No } \\
(\mathrm{N}=756)\end{array}$ & $\begin{array}{l}\text { Yes } \\
(\mathrm{N}=1,658)\end{array}$ & $\begin{array}{l}\text { P- } \\
\text { value }\end{array}$ & $\begin{array}{l}\text { No } \\
(\mathrm{N}=932)\end{array}$ & $\begin{array}{l}\text { Yes } \\
(\mathrm{N}=1,482)\end{array}$ & $\begin{array}{l}\text { P- } \\
\text { value }\end{array}$ \\
\hline & & $N(\%)$ & $\mathrm{N}(\%)$ & & $\mathrm{N}(\%)$ & $\mathrm{N}(\%)$ & \\
\hline
\end{tabular}

\section{Gender}

\begin{tabular}{llllllll} 
Male & $1,106(45.8)$ & $358(32.4)$ & $748(67.6)$ & 0.306 & $468(42.3)$ & $638(57.7)$ & 0.001 \\
\hline Female & $1,308(54.2)$ & $398(30.4)$ & $910(69.6)$ & & $464(35.5)$ & $844(64.5)$ &
\end{tabular}

\section{Age (years)}

\begin{tabular}{llllllll}
$19-44$ & $343(14.2)$ & $182(53.1)$ & $161(46.9)$ & $<0.001$ & $234(68.2)$ & $109(31.8)$ & $<0.001$ \\
\hline $45-64$ & $903(37.4)$ & $202(22.4)$ & $701(77.6)$ & $262(29.0)$ & $641(71.0)$ & \\
$\geq 65$ & $1,168(48.4)$ & $372(31.8)$ & $796(68.2)$ & $436(37.3)$ & $732(62.7)$ &
\end{tabular}

\section{Marital}

status

\begin{tabular}{|c|c|c|c|c|c|c|c|}
\hline Single & $329(13.6)$ & 187(56.8) & $142(43.2)$ & $<0.001$ & $251(76.3)$ & 78(23.7) & $<0.001$ \\
\hline Married & $1,721(71.3)$ & $419(24.3)$ & $1,302(75.7)$ & & $506(29.4)$ & $1,215(70.6)$ & \\
\hline $\begin{array}{l}\text { Other } \\
\text { (Divorced, } \\
\text { widowed, }\end{array}$ & $364(15.1)$ & $150(41.2)$ & $214(58.8)$ & & $175(48.1)$ & $189(51.9)$ & \\
\hline separated) & & & & & & & \\
\hline \multicolumn{8}{|l|}{$\begin{array}{l}\text { Area of } \\
\text { residence }\end{array}$} \\
\hline Capital area & $693(28.7)$ & $509(29.6)$ & $1,212(70.4)$ & 0.004 & $622(36.1)$ & $1,099(63.9)$ & $<0.001$ \\
\hline $\begin{array}{l}\text { Non-capital } \\
\text { area }\end{array}$ & $1,721(71.3)$ & $247(35.6)$ & $446(64.4)$ & & $310(44.7)$ & $383(55.3)$ & \\
\hline
\end{tabular}

\section{Education \\ level}

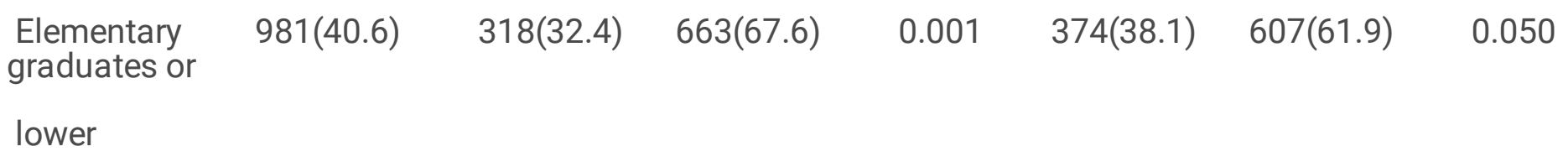

$\begin{array}{llllll}\begin{array}{l}\text { Middle } \\ \text { school } \\ \text { graduates }\end{array} & 305(12.6) & 74(24.3) & 231(75.7) & 98(32.1) & \text { 207(67.9) } \\ & & & & \end{array}$

\begin{tabular}{|cccccc}
$\begin{array}{l}\text { High school } \\
\text { graduates }\end{array}$ & $677(28.0)$ & $241(35.6)$ & $436(64.4)$ & $278(41.1)$ & $399(58.9)$ \\
\hline College & $451(18.7)$ & $123(27.3)$ & $\begin{array}{c}328(72.7) \\
\text { Page 6/15 }\end{array}$ & $182(40.4)$ & $269(59.6)$ \\
\hline
\end{tabular}


graduātes or

higher

\section{Occupation}

category

$\begin{array}{llllll}\text { White collar } \quad 265(11.0) & 58(21.9) \quad 207(78.1) & <0.001 & 98(37.0) & 167(63.0) & <0.001\end{array}$

$\begin{array}{llll}\text { Sales and } \quad 249(10.3) & 67(26.9) \quad 182(73.1) & \text { 84(33.7) }\end{array}$

service

Associates

$\begin{array}{llll}\text { Blue collar } \quad 685(28.4) & \text { 169(24.7) } \quad 516(75.3) & \text { 223(32.6) } & \text { 462(67.4) }\end{array}$

$\begin{array}{lllll}\text { Other } & 1,215(50.3) & 462(38.0) & 62.0(62.0) & \text { 527(43.4) }\end{array}$

(Students,

housewives,

unemployed)

\section{Income level \\ (million \\ KRW)}

$\begin{array}{llllllll}<2 & 1,267(52.5) & 427(33.7) & 840(66.3) & 0.029 & 493(38.9) & 774(61.1) & 0.830 \\ 2-4 & 646(26.8) & 186(28.8) & 460(71.2) & & 243(37.6) & 403(62.4) \\ >4 & 501(20.8) & 143(28.5) & 358(71.5) & 196(39.1) & 305(60.9)\end{array}$

\section{Subjective}

health status

\begin{tabular}{llllllll} 
Good & $599(24.8)$ & $187(31.2)$ & $412(68.8)$ & 0.061 & $246(41.1)$ & $353(58.9)$ & 0.072 \\
Moderate & $888(36.8)$ & $255(28.7)$ & $633(71.3)$ & & $317(35.7)$ & $571(64.3)$ \\
\hline Poor & $927(38.4)$ & $314(33.9)$ & $613(66.1)$ & & $369(39.8)$ & $558(60.2)$
\end{tabular}

\section{Subjective}

stress levels

\begin{tabular}{|c|c|c|c|c|c|c|c|}
\hline Very high & $173(7.2)$ & $60(34.7)$ & 113(65.3) & 0.303 & $78(45.1)$ & $95(54.9)$ & 0.137 \\
\hline High & $662(27.4)$ & 208(31.4) & $454(68.6)$ & & $245(37.0)$ & $417(63.0)$ & \\
\hline Low & $1,058(43.8)$ & $313(29.6)$ & $745(70.4)$ & & $396(37.4)$ & $662(62.6)$ & \\
\hline Very low & $521(21.6)$ & 175(33.6) & $346(66.4)$ & & $213(40.9)$ & $308(59.1)$ & \\
\hline \multicolumn{8}{|c|}{$\begin{array}{l}\text { Symptoms } \\
\text { of } \\
\text { depression }\end{array}$} \\
\hline No & 788(32.6) & 198(25.1) & $590(74.9)$ & $<0.001$ & $273(34.6)$ & $515(65.4)$ & 0.005 \\
\hline Yes & $1,626(67.4)$ & $558(34.4)$ & $1,068(65.7)$ & & $659(40.5)$ & $967(59.5)$ & \\
\hline
\end{tabular}




\begin{tabular}{|llllllll|} 
No & $937(38.8)$ & $347(37.0)$ & $590(63.0)$ & $<0.001$ & $432(46.1)$ & $505(53.9)$ & $<0.001$ \\
\hline Yes & $1,477(61.2)$ & $409(27.7)$ & $1,658(72.3)$ & & $500(33.9)$ & $977(66.1)$ & \\
\hline
\end{tabular}

\section{Factors associated with health checkups and cancer screening participation among family caregivers of individuals with dementia}

Table 3 shows the results of a binomial logistic regression for identifying factors associated with health checkups and cancer screening participation. Health checkups participation was higher among individuals who were women $(\mathrm{OR}=1.30$ ), older ( $45-64$ years $\mathrm{OR}=2.70, \geq 65$ years $\mathrm{OR}=2.49)$, married, and other(divorced, widowed, separated) as opposed to individuals who were single (married $\mathrm{OR}=3.22$, other $\mathrm{OR}=1.63$ ), and having one or more chronic diseases $(\mathrm{OR}=1.47)$. On the other hand, health checkup participation was lower among elementary school graduates or lower and high school graduates compared to college graduates or higher (elementary school graduates or lower $\mathrm{OR}=0.60$, high school graduates $\mathrm{OR}=0.63$ ), sales and service associates, blue collar, and other(students, housewives, unemployed) compared to white collar (sales and service associates $\mathrm{OR}=0.58$, blue collar $\mathrm{OR}=0.56$, other $\mathrm{OR}=0.31$ ), among those who had symptoms of depression $(\mathrm{OR}=0.67)$.

Cancer screening participation was higher among women ( $O R=1.61)$, older individuals (45-64 years $\mathrm{OR}=2.77, \geq 65$ years $\mathrm{OR}=2.56$ ), married individuals, and other compared to individuals who were single (married $\mathrm{OR}=6.08$, other $\mathrm{OR}=2.87$ ). Cancer screening rate was lower among individuals who live in noncapital area( $\mathrm{OR}=0.80)$, had a lower education level (elementary school graduates or lower $\mathrm{OR}=0.59$ ), and other compared to white collar $(\mathrm{OR}=0.46)$, and those who had symptoms of depression $(\mathrm{OR}=0.65)$. 
Table 3

Factors associated with health checkups and cancer screening participation among family caregivers of individuals with dementia

\begin{tabular}{|c|c|c|c|c|}
\hline \multirow[t]{2}{*}{ Variable } & \multicolumn{2}{|c|}{ Health checkups } & \multicolumn{2}{|c|}{ Cancer screening } \\
\hline & OR & $95 \% \mathrm{Cl}$ & OR & $95 \% \mathrm{Cl}$ \\
\hline \multicolumn{5}{|l|}{ Gender } \\
\hline Male ${ }^{a}$ & 1.00 & & 1.00 & \\
\hline Female & $1.30^{*}$ & $1.06-1.60$ & $1.61^{\star \star \star}$ & $1.32-1.97$ \\
\hline \multicolumn{5}{|l|}{ Age } \\
\hline $19-44$ years $^{a}$ & 1.00 & & 1.00 & \\
\hline $45-64$ years & $2.70^{\star \star \star}$ & $1.89-3.86$ & $2.77^{\star \star \star}$ & $1.95-3.95$ \\
\hline$\geq 65$ years & $2.49^{\star \star \star}$ & $1.59-3.90$ & $2.56^{\star \star \star}$ & $1.65-3.97$ \\
\hline \multicolumn{5}{|l|}{ Marital status } \\
\hline Single $e^{a}$ & 1.00 & & 1.00 & \\
\hline Married & $3.22^{\star \star \star}$ & $2.27-4.57$ & $6.08^{\star \star \star}$ & $4.25-8.69$ \\
\hline $\begin{array}{l}\text { Other (Divorced, } \\
\text { widowed, separated) }\end{array}$ & $1.63^{*}$ & $1.09-2.45$ & $2.87^{\star \star \star}$ & $1.90-4.32$ \\
\hline \multicolumn{5}{|l|}{ Area of residence } \\
\hline Capital area ${ }^{a}$ & 1.00 & & 1.00 & \\
\hline Non-capital area & 0.82 & $0.67-1.01$ & $0.80^{*}$ & $0.65-0.98$ \\
\hline \multicolumn{5}{|l|}{ Education level } \\
\hline $\begin{array}{l}\text { College graduates or } \\
\text { higher }^{\mathrm{a}}\end{array}$ & 1.00 & & 1.00 & \\
\hline High school graduates & $0.63^{\star \star}$ & $0.46-0.85$ & 0.79 & $0.58-1.07$ \\
\hline Middle school graduates & 0.79 & $0.53-1.18$ & 0.74 & $0.51-1.08$ \\
\hline $\begin{array}{l}\text { Elementary graduates or } \\
\text { lower }\end{array}$ & $0.60^{\star *}$ & $0.42-0.86$ & $0.59^{\star \star}$ & $0.42-0.84$ \\
\hline \multicolumn{5}{|l|}{ Occupation category } \\
\hline White collar ${ }^{a}$ & 1.00 & & 1.00 & \\
\hline Sales and service & & $0.36-0.93$ & 0.76 & $0.49-1.19$ \\
\hline
\end{tabular}




\begin{tabular}{|c|c|c|c|c|}
\hline \multirow{2}{*}{$\begin{array}{l}\text { associates } \\
\text { Blue collar }\end{array}$} & \multicolumn{4}{|l|}{$0.58^{*}$} \\
\hline & $0.56^{\star \star}$ & $0.37-0.85$ & 0.71 & $0.48-1.05$ \\
\hline $\begin{array}{l}\text { Other (Students, } \\
\text { housewives, unemployed) }\end{array}$ & $0.31^{\star \star \star}$ & $0.21-0.47$ & $0.46^{\star \star \star}$ & $0.31-0.68$ \\
\hline \multicolumn{5}{|l|}{ Income level } \\
\hline$>4$ million KRW ${ }^{\mathrm{a}}$ & 1.00 & & 1.00 & \\
\hline 2-4 million KRW & 0.93 & $0.69-1.24$ & 1.00 & $0.76-1.32$ \\
\hline$<2$ million KRW & 0.81 & $0.61-1.07$ & 0.96 & $0.66-1.19$ \\
\hline \multicolumn{5}{|l|}{ Subjective health status } \\
\hline Good $^{a}$ & 1.00 & & 1.00 & \\
\hline Moderate & 0.98 & $0.76-1.28$ & 1.01 & $0.79-1.32$ \\
\hline Poor & 0.88 & $0.65-1.18$ & 0.96 & $0.72-1.27$ \\
\hline \multicolumn{5}{|l|}{ Subjective stress levels } \\
\hline Very higha & 1.00 & & 1.00 & \\
\hline High & 0.83 & $0.55-1.25$ & 0.98 & $0.66-1.46$ \\
\hline Low & 1.05 & $0.72-1.53$ & 1.28 & $0.89-1.85$ \\
\hline Very low & 1.06 & $0.72-1.54$ & 1.36 & $0.94-1.97$ \\
\hline \multicolumn{5}{|l|}{ Symptoms of depression } \\
\hline $\mathrm{No}^{\mathrm{a}}$ & 1.00 & & 1.00 & \\
\hline Yes & $0.67^{\star \star \star}$ & $0.54-0.82$ & $0.65^{\star \star *}$ & $0.53-0.80$ \\
\hline \multicolumn{5}{|l|}{ Chronic disease } \\
\hline $\mathrm{No}^{\mathrm{a}}$ & 1.00 & & 1.00 & \\
\hline Yes & $1.38^{\star \star}$ & $1.10-1.74$ & 1.25 & $1.00-1.56$ \\
\hline 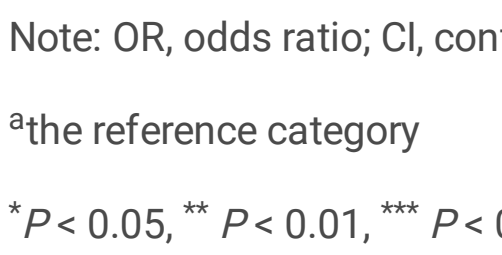 & idence in & erval & & \\
\hline
\end{tabular}

\section{Discussion}


This study aimed to examine the current health checkup and cancer screening rates in family caregivers of individuals with dementia and to identify factors associated with their participation in health checkups and cancer screening. The health checkups and cancer screening rates among family caregivers of individuals with dementia were lower than those without dementia. This may be consistent with our assumption that family caregivers of individuals with dementia may not spare some time to go for health checkups or cancer screening because of their informal care burden and consequent burnout. Considering that they may experience various health issues $[7,8]$, not participating in health checkups or cancer screening more actively may aggravate existing conditions and defer timely treatment and management of diseases.

Among the factors associated with health checkups and cancer screening, most of them are consistent with previous studies; however, some of them stand out. In terms of demographic factors, health checkups and cancer screening rates were higher among women than among men. This seems to be influenced by men's lack of time to undergo health checkups because they traditionally perform more social and economic activities than women do in Korea [19]. Further, the tendency of men to have a lower awareness and/or willingness to undergo health checkups may be another cause. In terms of age, older people showed a higher health checkups rate, which was consistent with previous findings where non-participation in cancer screening and general exams were higher among relatively younger people [19]. This seems to be attributable to the fact that many individuals in their sixties or older are retirees, thus having much more spare time. Additionally, people have increased needs and awareness of health checkups as they age as a result of increased exposure to chronic disease and opportunities of obtaining information about health management [21]. In terms of marital status, health checkups rate was higher among married individuals and those with "other" marital status compared to singles, which supports a previous finding that people with a spouse show relatively increased health checkups behaviors [17]. Married people would have been motivated for health checkups by their spouse as the head of their family, suggesting that spousal encouragement and support are needed to increase health checkups participation [22].

In terms of education level, health checkups rate was lower among elementary school graduates middle or lower and high school graduates compared to college graduates or higher; also, cancer screening rate decreased with decreasing education level. This could be explained by the previous finding that college graduates or higher are sufficiently aware of the benefits of health checkups and that they voluntarily seek health checkups [23]. Further, because education level is closely related to health behaviors, attitudes, and knowledge in general, more educated people receive health checkups as an effort to improve their lifestyles and continue living a healthy life [24]. There is a need for low-level caregivers to be able to comprehensively identify and understand their unmet health needs and to have easy access to support because of the potential lack of access to healthcare and caregiver support [25]. Therefore, healthcare researchers and policy makers should be aware of these marginalized groups and should take them into consideration when developing policy goals and support for family caregivers with dementia [25].

In terms of occupation category, sales and service associates, blue collar, and other showed a lower health checkups rate compared to white collar, while sales and service associates and blue collar showed a lower cancer screening rate. This was similar to previous findings that health checkup rates are higher among office workers [26]. 
In terms of health status factors, health checkup and cancer screening rates were lower in people who had symptoms of depression. We can speculate that people who have stress and depression show demotivation and reduced activity, which might have hindered their engagement in health checkups [27]. Depression is often associated with medical use, but the prevalence of depression in family caregivers with dementia is high, so it is something essential to consider when doing interventions with caregiving [28]. In other words, attention should be drawn to psychological factors such as depression, and strategies should be developed to increase the health checkups and cancer screening rate of family caregivers with dementia [6-8]. Health checkups rates were higher among those with a chronic disease, presumably because the need for continued attention to health and health management increased after being diagnosed with a chronic disease [16].

This study had several limitations. First, we could not examine causal relationships over time due to the use of a cross-sectional design. Second, the KCHS used in this study was a self-reported survey with bias. Third, in cancer screening, the number of participants and period varied; thus, it was not possible to analyze this due to lack of secondary data.

Despite these limitations, the significance of this study lies in that it provides baseline data and implications for improving existing policies and developing new policies to increase health checkups and cancer screening participation in family caregivers of individuals with dementia. To ensure a healthy life for families providing care, it is important to check their health routinely to detect and treat abnormalities early to prevent them from developing further complications. In particular, this study revealed that the physical and mental health status of family caregivers of individuals with dementia is closely associated with the health checkups and cancer screening. This was achieved by analyzing factors associated with their participation in health checkups and cancer screening amid a lack of existing research data on health checkupsassociated with factors in family caregivers of individuals with dementia in Korea.

The goal of this study was to analyze factors associated with health checkups and cancer screenings of family caregivers of individuals with dementia in Korea through national-level data. The finding that family caregivers of individuals with dementia, particularly those with lower education level and symptoms of depression, were less likely to go for health checkups and cancer screening warrants developing more targeted disease prevention and management strategies. Further research on health checkups and cancer screenings of family caregivers of individuals with dementia is required to address the current lack of information on health screening behaviors in order promote the physical and mental health of those who are directly involved in the care of dementia patients.

\section{Abbreviations}

KCHS: Korea Community Health Survey; KCDC: Korea Centers for Disease Control and Prevention; CAPI: Computer-assisted personal interviewing; KRW: Korean Won; PHQ-9: Patient Health Questionnaire-9; OR: Odds ratio; $\mathrm{Cl}$ : Confidence intervals

\section{Declarations}




\section{Acknowledgements}

Not applicable.

\section{Author's contributions}

BK and THK directly participated in the planning, execution, and analysis of the study. YL, and J-WN participated in the design of the study and performed the statistical analysis. All authors read and approved the final manuscript.

\section{Funding}

This research did not receive any specific grant from funding agencies in the public, commercial, or not-forprofit sectors.

\section{Availability of data and materials}

Detailed information on the survey design and characteristics are provided at https://chs.cdc.go.kr/chs/index.do, and the KCHS data is publicly avilable from the link.

\section{Ethics approval and consent to participate}

Not applicable.

\section{Consent for publication}

Not applicable.

\section{Competing interests}

The authors declare that they have no competing interests.

\section{Author's details}

${ }^{1}$ Department of Public Health, Graduated School, Yonsei University, 50-1 Yonsei-ro, Seodaemun-gu, Seoul 03722, Republic of Korea. ${ }^{2}$ Department of Healthcare management, Graduated School, Eulji University, 553 Sanseong-daero, Seongnam-si, Gyeonggi-do 13135, Republic of Korea. ${ }^{3}$ Department of Health Administration, Dankook University, 119 Dandae-ro, Cheonan-si, Chungcheongnam-do 31116, Republic of 
Korea. ${ }^{4}$ Department of Healthcare Management, Graduate School of Public Health, Yonsei University, 50-1 Yonsei-ro, Seodaemun-gu, Seoul 03722, Republic of Korea.

\section{References}

1. National Institute of Dementia. Korean Dementia Observatory 2018. Seoul: National Institute of Dementia; 2019.

2. Kim YE. A study of support policy for families having elderly dementia. J Korean Long Term Care. 2016;4(1):80-100.

3. Toseland RW, McCallion P, Gerber T, Banks S. Predictors of health and human services use by persons with dementia and their family caregivers. Soc Sci Med. 2002;55(7):1255-66.

4. Gitterman A. Handbook of social work practice with vulnerable and resilient populations. New York: Columbia University Press; 2014.

5. Schulz R. Handbook on dementia caregiving: Evidence-based interventions for family caregivers. New York: Springer Publishing Co; 2000.

6. Cho EY, Cho EH, Kim SS. Effects of family relationship on burden of family caregivers of older adult with dementia. J Korea Gerontol Soc. 2010;30(2):421-37.

7. Park CS, Chung WM, Oh HC. Analysis of caregiver needs for home-based occupational therapy program for elderly community dwellers with dementia based on symptom level and caregiver burden. J Korean Soc Occup Ther. 2010;18(4):51-62.

8. Clipp EC, George LK. Dementia and cancer: a comparison of spouse caregivers. Gerontologist. 1993;33(4):534-41.

9. Do YK, Norton EC, Stearns SC, Van Houtven CH. Informal care and caregiver's health. Health Econ. 2015;24(2):224-37.

10. The Korean Journal of Family Practice. Textbook of family medicine. Seoul: Korean Medicine; 2007.

11. Kim RB, Park KS, Hong DY, Lee CH, Kim JR. (2010). Factors associated with cancer screening intention in eligible persons for national cancer screening program. J Prev Med Public Health. 2010;43(1):62-72.

12. Broyles R, Narine L, Brandt E, Biard-Holmes D. Health risks, ability to pay, and the use of primary care: is the distribution of service effective and equitable? Prev Med. 2000;30(6):453-62.

13. Langlie JK. Social networks, health beliefs, and prevention health behavior. J Health Soc Behav. 2007;8(3):244-60.

14. Yang YH. A path analysis on factors influencing second primary cancer screening practices in stomach, colon, and breast cancer survivors. J Korean Acad Nurs. 2014;44(2):139-48.

15. Yeo JY, Chung HS. Determinants of health screening and its effects on health promotion behaviors. Health Policy Manag. 2012;22(1):49-64.

16. Kang SW, Yoo CH, Kwon YD. The determinants of the use of opportunistic screening programs in Korea. J Prev Med Public Health. 2009;42(3):177-82.

17. Lee SA, Choi KS, Hwang SY, et al. The effect of socioeconomic factors on health screening in Korea: the 2001 Korean National Health and Nutrition Examination Survey (KNHANES). J Korean Assoc Cancer 
Prev. 2004;9(3):188-98.

18. Kwak MS, Park EC, Bang JY, Sung NY, Lee JY, Choi KS. Factors affecting cancer screening participation. J Prev Med Public Health. 2005;38(4):473-81.

19. Sung NY, Park EC, Shin HL, Choi KS. Participation rate and related sociodemographic factors in the national cancer screening program. Korean J Prev Med. 2005;38(1):93-100.

20. Korea Centers for Disease Control and Prevention Korea. 2017 Guideline for using the Community Health Survey data. Chungbuk: Korea Centers for Disease Control and Prevention, 2017; 1-210.

21. Yang SE, Han NK, Lee SM, Kim TH, Chung WJ. The factors related to the non-practice of cancer screening in cancer survivors: Based on the 2007-2012 Korean National Health and Nutrition Examination Survey. Health Policy Manag. 2005;25(3):162-73.

22. Choi EJ, Kim DJ, Lee WC, Hwang IY. Establishment of an efficient management system for advanced outcome of the National Health Screening Policy. Seoul: Korea Institute for Health Social Affairs; 2009.

23. Mun YO, Park EC, Kwak MS, Choi KS, Kim SG, Hahm MI. The Relationship Between Socioeconomic Status and Self-rated Health Among Korean Population Needed to Have Cancer Screening. Korean J Health Promot Dis Prev. 2007;7(3):157-64.

24. Lantz PM, House JS, Lepkowski JM, Williams DR, Mero RP, Chen J. Socioeconomic factors, health behaviors, and mortality: results from a nationally representative prospective study of US adults. JAMA. 1998;279(21):1703-8.

25. Zwingmann I, Michalowsky B, Esser A, Kaczynski A, Monsees J, Keller A, et al. Identifying unmet needs of family dementia caregivers: results of the baseline assessment of a cluster-randomized controlled intervention trial. J Alzheimers Dis. 2019;67(2):527-39.

26. Choi WM, Han NK, Chung WJ. Factors associated with the non-screening status of cervical cancer screening test in Korean adult women: Korea National Health and Nutrition Examination Survey (20102012). Health Policy Manage. 2019;29(4):399-411.

27. Kim MG. A study on the characteristics of depression of elderly according to gender. The JKAFA. $2015 ; 7(2): 1-6$.

28. Martindale-Adams J, Nichols LO, Zuber J, Burns R, Graney MJ. Dementia caregivers' use of services for themselves. Gerontologist. 2016;56(6):1053-61. 